\title{
Knowledge Level and Beliefs of Patients and Their Relatives about Hypnosis and Their Attitudes toward Use of Hypnosis for Sedation and Analgesia Purposes in the Emergency Department
}

\author{
(1) Harun Güneș ${ }^{1}$, (1) Serhat Koyuncu ${ }^{2}$ \\ 1Department of Emergency Medicine, Balıkesir University School of Medicine, Balıkesir, Turkey \\ 2Department of Emergency Medicine, Gaziosmanpașa University School of Medicine, Tokat, Turkey
}

\begin{abstract}
Aim: To evaluate the knowledge level and beliefs of patients and their relatives about hypnosis and their attitudes toward use of hypnosis for sedation and analgesia purposes in the emergency department.

Materials and Methods: The study was conducted as a two-center study. The total number of participants recruited into the study was 384. A questionnaire including socio-demographic features, sources of information, knowledge and beliefs about hypnosis, and attitudes of participants toward the use of hypnosis in the emergency department in different clinical scenarios was used. Overall results of total study sample and differences between various sub-groups were evaluated.

Results: Mean age of participants was 34.27 years. Two hundred and sixteen (56.3\%) participants were male. Television was the source of information with the highest effect on the knowledge of participants about hypnosis. Participants were seen to mostly believe myths about hypnosis. They preferred hypnosis only in the case of the existence or possibility of drug dependence (mean \pm standart deviation=3.78 \pm 1.979 ).

Conclusion: Participants were mostly misled by improper sources of information so they were seen to be reluctant to prefer hypnosis in all clinical scenarios other than the existence or possibility of drug dependence.
\end{abstract}

Keywords: Analgesia, attitude, emergency department, hypnosis, knowledge level, sedation

\section{Introduction}

Although the word hypnosis is derived from the Greek "hypnos", meaning sleep, it is actually a state of highly focused awareness (1). It is an altered, but not decreased, state of consciousness during which an individual is able to have an elevated control over sensory modalities through suggestion and imagination. Hypnotist does not control the patient but guides the patient's ability to control his or her own sensory state (2). Hypnosis has been used in modern medicine for more than two centuries. Besides, it fulfills nearly all requirements of the ideal emergency department (ED) intervention; it is safe, fast, readily available, cost effective, uses minimal personnel and equipment, and has no risks like infection, prolonged sedation or other risks associated with sedation or medication administration $(1,3)$. Emergency physicians (EP) are presented daily with patients in pain. Provision of safe and quick pain control remains one of their major duties. Hypnosis can be used as an effective adjunct or substitute for analgesic medications when these drugs prove to be ineffective or contraindicated (2). Because there is no physiological or psychological danger unique to hypnosis, it is unlikely that the circumstances surrounding the use of hypnosis in an acute medical situation would lead to any adverse complication. The $E D$, where patients in pain or with fear are frequently treated,

Cite this article as: Güneș H, Koyuncu S. Knowledge Level and Beliefs of Patients and Their Relatives about Hypnosis and Their Attitudes toward Use of Hypnosis for Sedation and Analgesia Purposes in the Emergency Department. Eurasian J Emerg Med. 2021;20(1):25-34.

(C) Copyright 2021 by the Emergency Medicine Physicians' Association of Turkey

Eurasian Journal of Emergency Medicine published by Galenos Publishing House. 
represents one area in which hypnosis could be an effective modality (3). The conditions where hypnosis can be used in ED include providing analgesia for existing pain (e.g. fractures, burns and lacerations), providing analgesia and sedation for painful procedures (e.g. needle sticks, laceration repair, and fracture and joint reductions), reducing acute anxiety, increasing children's cooperation for procedures, and providing analgesia and sedation for obstetric/gynecologic problems and even for myocardial infarction (1,4-8). Well, we have a critical question: Is hypnosis really effective against pain? The answer is yes; imaging studies show that pain under hypnosis is not perceived, rather than simply being experienced with greater tolerance (1). The analgesic effect of hypnosis is not solely a placebo effect which can suppress pain in $20-30 \%$ of individuals (2). Placebo appears to work through the endogenous opiate system and can be blocked by naloxone (9). Hypnosis is a modulator of pain, and its analgesic effect been shown to not be blocked by this agent (10). The use of hypnosis, instead of or in combination with drugs, for purposes of sedation and analgesia will be particularly more beneficial in the case of pregnancy, liver or renal insufficiency, or history of drug allergy or abuse. Articles that discuss ED use of hypnosis have sporadically appeared over the past several decades but most of the physicians have been reluctant to use this technique in the practice $(2,3,11-16)$. This is due, in part, to the myths surrounding hypnosis and its association with alternativecomplementary medicine. Major barriers to its more common clinical use in ED include lack of training and concerns of EPS about reluctance of patients and their relatives to accept the use of hypnosis. Based on the results of further research, hypnosis could become a powerful and safe non-pharmacologic addition to the EP's arsenal, with the potential to enhance patient care in emergency medicine (EM) (1). First, investigational studies are needed to identify how hypnosis can best be used in EM, and one of the potential study areas is evaluation of the attitude of ED patients and their relatives towards hypnosis. To the best of our knowledge, there are no previous studies investigating the knowledge level and beliefs of ED patients and their relatives about hypnosis and their attitudes towards use of hypnosis for purposes of sedation and analgesia in ED. So, the present study was performed to evaluate this topic.

\section{Materials and Methods}

The study was performed on patients and their relatives admitted to Düzce University Hospital Emergency Department in Düzce or Gaziosmanpaşa University Hospital Emergency Department in Tokat. It was conducted, instead of a single-center study, as a two-center study in order to reach more reliable results which reflect the population's knowledge level, beliefs and attitudes more accurately. Düzce and Tokat are $600 \mathrm{~km}$-apart cities one of which is located in the western-half (Düzce) and the other one in the eastern-half of the country (Tokat).

Determination of the Sample Size: The sample size of the study was determined as 384 participants by using sample size calculation formula for known population. The universe of the study population $(\mathrm{N})$ was nearly 600,000 people which was the number of the sum of the population between 18 and 65 years of age living in Düzce and Tokat according to 2016 data provided by Turkish Statistical Institute. When calculating the sample size, the following assumptions were used; confidence interval $(\mathrm{Cl})=95 \%, \alpha=0.05, p=0.5$ and $\mathrm{q}=0.5$. Half of the participants $(n=192)$ were recruited from Düzce and the other half $(n=192)$ were from Tokat.

Data Collection: The data was gathered using a single-page questionnaire which is provided as a supplement of this paper. It included:

1. Socio-demographic features (e.g. age, gender, previous hypnosis experience, education level, sources of information on hypnosis),

2. Fourteen Likert type statements on knowledge and beliefs about hypnosis - present in the supplemental document - (1 point means absolutely disagree, 2 points mean disagree, 3 points mean mildly disagree, 4 points mean mildly agree, 5 points mean agree and 6 points mean absolutely agree),

3. Seven Likert type statements related to preference of use of hypnosis in ED for purposes of sedation and analgesia (in the case of application to the participant; to a pregnant/breastfeeding/child relative of the participant, or to a relative with liver or renal insufficiency/drug allergy/drug abuse history). (Having the same scoring system with the previous item),

4. A mean value of 3.5 which is the arithmetic mean of 3 and 4 points (the highest disagree point and the lowest agree point, respectively) for Likert type statements was the cutoff value between "agree" and "disagree" decisions. The questionnaire was mostly based on the one used in the study by Johnson and Hauck (17). The questionnaire was applied to participants randomly in order to prevent selection bias. The data collection was completed between March, 2017 and June, 2019.

Inclusion and Exclusion Criteria: The inclusion criteria were as follows: Being a patient admitted to ED or a relative of the patient treated in ED, giving permission and written informed consent to participate in the study. And, the exclusion criteria were as follows: being under 18 or over 65 years of age, illiteracy, blindness, deafness, mental retardation, having an emergent 
problem not allowing to fill in the questionnaire or being a patient the clinical condition of whom is unstable or being the relative of such a patient and feeling anxious due to the concerns about the outcome of the patient.

Sub-groups: Participants were grouped in terms of the city the participant lives in, gender, age (young: 18-25 years; younger adults: 26-40 years; middle-aged adults: 41 years and older), education level, occupations and prior hypnosis experience. The differences in the knowledge level and beliefs about hypnosis and attitudes towards its use in the ED for purposes of sedation and analgesia in different clinical scenarios were evaluated. Besides, attitudes of the participants towards use of hypnosis in the emergency department were compared in different city, gender, age, education level, occupation and sources of information groups.

The study had been approved by Local Research Ethics Committee in [Düzce University Non-invasive Health Studies Ethics Committee, (approval number: 2017/46, approval date: 06.03.2017)].

\section{Statistical Analysis}

The descriptive statistics of all variables were calculated. The Kolmogorov-Smirnov test was used to evaluate whether the distribution of continuous variables was normal. The results were presented as mean \pm standard deviation (SD) for continuous variables, and number $(n)$ and percentages (\%) for categorical variables. For normally distributed variables; means of two different groups were compared with Student's t-test; One-Way ANOVA (Bonferroni test) was used for comparison of multiple groups. And, means of previously-hypnotized and non- hypnotized groups were compared with Mann-Whitney U test due to the extremely small number of participants in the previouslyhypnotized group. Categorical variables were compared with chisquare test. Statistical analyses were performed using the IBM SPSS Statistics for Windows v.25 (IBM Inc., New York, NY, USA). For all of the statistical tests, a p-value below 0.05 was considered significant.

\section{Results}

The first part of the questionnaire was about socio-demographic features. Mean age of the participants was $34.27 \pm 12.644$ years; 132 (34.4\%) participants were between 18 and 25 years old (young group); 136 (35.4\%) were between 26 and 40 years old (younger adults), and 115 (29.9\%) were 41 years old or older (middle-aged adults); differences among the numbers of the participants in different age groups were found to be non-significant $(p=0.473)$. Gender distribution of the participants were as follows: male: $n=216,56.3 \%$; female: $n=167,43.5 \%$; missing: $n=1,0.3 \%$; difference between the numbers of male and female participants was found to be non-significant $(p=0.476)$. Only $3.4 \%(n=13$,$) of$ the participants had been hypnotized previously; 369 (96.1\%) participants had not had any prior hypnosis experience, and 2 $(0.5 \%)$ patients did not respond to this item. The largest education level group was formed by high school graduates ( $n=136,35.4 \%$ ), and the largest occupation group was wage workers $(n=153$, $39.8 \%$ ). Table 1 shows distribution of the participants into the education level and occupation groups.

The source of information having the highest effect on the knowledge of the participants on hypnosis was seemed to be television (no influence: $n=153,39.8 \%$; some influence: $n=78$,

\begin{tabular}{|c|c|c|c|}
\hline Main parameter & Subgroups & $n$ & $\%^{*}$ \\
\hline \multirow{4}{*}{ Education level } & Literate & 9 & 2.3 \\
\hline & Secondary school graduate & 47 & 12.2 \\
\hline & High school graduate & 136 & 35.4 \\
\hline & Missing & 3 & 0.8 \\
\hline \multirow{3}{*}{ Occupation } & Wage worker & 153 & 39.8 \\
\hline & Student & 74 & 19.3 \\
\hline & Housewife & 58 & 15.1 \\
\hline
\end{tabular}


20.3\%; most influence: $n=151,39.3 \%$; missing: $n=2,0.5 \%)$. Table 2 summarizes the sources of information on the knowledge of the participants about hypnosis.

The participants were given 14 Likert type statements about hypnosis and it was seen that means of the answers were above 3.5 for most of the statements which means they agree with the statement. However, most of these statements were about common myths related to hypnosis. Table 3 summarizes the beliefs and thoughts of the participants about these statements.

The last part of the questionnaire included 7 Likert type statements about preference of hypnosis by the participant in different clinical scenarios. It was seen that mean of the participants' responses was higher than 3.5 in one statement only. That statement was "I prefer hypnosis to be applied if drug dependence or possibility of dependence exists (mean \pm SD: $3.78 \pm 1.979$ ). Table 4 shows the results of the participants' preferences about use of hypnosis in different clinical conditions.

When the attitudes of the participants towards use of hypnosis in ED were compared in terms of the city the participant lives in, gender, age groups, education level, occupation groups and hypnosis experience, it was seen that gender, age group, occupation and hypnosis experience do not have a significant effect on the attitude of the participant towards use of hypnosis. However, the city the participant lives in seemed to affect the preference of the participant in all suggested scenarios except application of hypnosis to the participant's himself or to a breast-

Table 2. Roles of different sources of information on knowledge of the participants about hypnosis

\begin{tabular}{|l|l|l|l|}
\hline \multirow{2}{*}{ Information source } & \multicolumn{3}{|c|}{ Effect on knowledge about hypnosis (n - \%) } \\
\cline { 2 - 4 } & No influence & Some influence & Most influence \\
\hline Television & $153-39.8 \%$ & $78-20.3 \%$ & $151-39.3 \%$ \\
\hline Movies & $248-64.6 \%$ & $71-18.5 \%$ & $63-16.4 \%$ \\
\hline Rumors & $257-66.9 \%$ & $73-19.0 \%$ & $52-13.5 \%$ \\
\hline Hypnosis shows & $293-76.3 \%$ & $35-9.1 \%$ & $54-14.1 \%$ \\
\hline Clinicians & $296-77.1 \%$ & $33-8.6 \%$ & $53-13.8 \%$ \\
\hline Friends & $306-79.7 \%$ & $48-12.5 \%$ & $28-7.3 \%$ \\
\hline Teachers & $344-89.6 \%$ & $27-7.0 \%$ & $11-2.9 \%$ \\
\hline Other & $345-89.8 \%$ & $28-7.3 \%$ & $9-2.3 \%$ \\
\hline $\begin{array}{l}\text { n: Number } \\
*\end{array}$ The percentages are rounded off to the nearest decimal & & $2-0.5 \%$ \\
\hline
\end{tabular}

Table 3. Thoughts of the participants about some statements related to hypnosis

\begin{tabular}{|l|l|}
\hline Statement & $\begin{array}{l}\text { Participants' thoughts } \\
\text { (mean } \pm \text { SD) }\end{array}$ \\
\hline Hypnotized person has an altered level of consciousness & $3.85 \pm 1.753$ \\
\hline Hypnosis is like sleeping & $4.13 \pm 1.621$ \\
\hline Hypnotized person is totally controlled by the hypnotist & $4.13 \pm 1.677$ \\
\hline Hypnotized person can be made to do something which he or she will not do normally & $4.06 \pm 1.676$ \\
\hline A person can be hypnotized even if he does not want to be & $3.31 \pm 1.733$ \\
\hline Hypnotized person does not feel any pain & $3.66 \pm 1.709$ \\
\hline Hypnotized person can terminate the hypnotic state whenever he wants to do so & $2.77 \pm 1.671$ \\
\hline All secrets of a hypnotized person can be learned by the hypnotist & $3.91 \pm 1.658$ \\
\hline Hypnotized person cannot lie & $3.79 \pm 1.736$ \\
\hline Hypnotized person sometimes do not know what is going on around him or her & $4.06 \pm 1.550$ \\
\hline Hypnotized person forgets what happened during hypnotic state if he is ordered to do so & $3.56 \pm 1.720$ \\
\hline Hypnosis is formed by the person's own imagination & $3.34 \pm 1.657$ \\
\hline Deeply hypnotized ones are likely to forget what happened during hypnotic state & $3.78 \pm 1.571$ \\
\hline Hypnosis makes someone able to do tasks which are normally impossible & $3.98 \pm 1.617$ \\
\hline SD: Standard deviation & \\
\hline
\end{tabular}


feeding relative ( $p \leq 0.05$ for all scenarios except application to the participant's himself and a breast feeding relative, for the latter two scenarios $p=0.061$ and $p=0.112$, respectively). Table 5 includes the attitudes of the participants living in different cities towards the use of hypnosis in ED. Besides, education level seemed to affect the preference of the participants in the case of renal or liver insufficiency $(p=0.013)$ (Table 6).

\section{Discussion}

In the current study, which did not include pediatric (below 18 years old) and older adult (older than 65 years of age) populations, the participants were nearly equally distributed among the young, younger adult and middle-aged adult groups. Gender distribution of the participants also was near equal. A really small minority of the participants was seen to have previous personal experience of hypnosis. Nearly all of the participants were at least primary school graduates. Wage workers which included all participants having a paid job formed more than one third of the participants. Most of the participants stated that television somewhat affected their knowledge on hypnosis. The participants were seemed to generally agree with the common myths about hypnosis. A striking finding of the study was that the participants were not likely to prefer hypnosis in any clinical scenario except the existence or possibility of drug dependence. Gender, age, occupation and hypnosis experience were seen to not have a significant effect on the attitude of the participant towards use of hypnosis in ED. Two independent variables only, namely the city the participant lives in and education level of the participant, were seen to affect the preference of the participants in some clinical scenarios.

Distribution of the study population among the young, younger adult and middle-aged adult groups was near equal; each group

Table 4. The participants' attitudes towards the use of hypnosis in different scenarios

\begin{tabular}{|l|l|}
\hline Statement & $\begin{array}{l}\text { Attitudes of participants } \\
\text { (mean } \pm \text { SD) }\end{array}$ \\
\hline I prefer hypnosis to be applied to myself & $2.86 \pm 1.912$ \\
\hline I prefer hypnosis to be applied to a pregnant relative of mine & $2.60 \pm 1.815$ \\
\hline I prefer hypnosis to be applied to my child or a child relative of mine & $2.62 \pm 1.816$ \\
\hline I prefer hypnosis to be applied to a relative with renal or liver insufficiency & $2.92 \pm 1.842$ \\
\hline I prefer hypnosis to be applied to a breast-feeding relative of mine & $2.76 \pm 1.808$ \\
\hline I prefer hypnosis to be applied in the case of drug allergy & $3.32 \pm 1.929$ \\
\hline I prefer hypnosis to be applied if drug dependence or possibility of dependence exists & $3.78 \pm 1.979$ \\
\hline SD: Standard deviation & \\
\hline
\end{tabular}

Table 5. Effect of the city the participant lives in on the preference of hypnosis by the participant

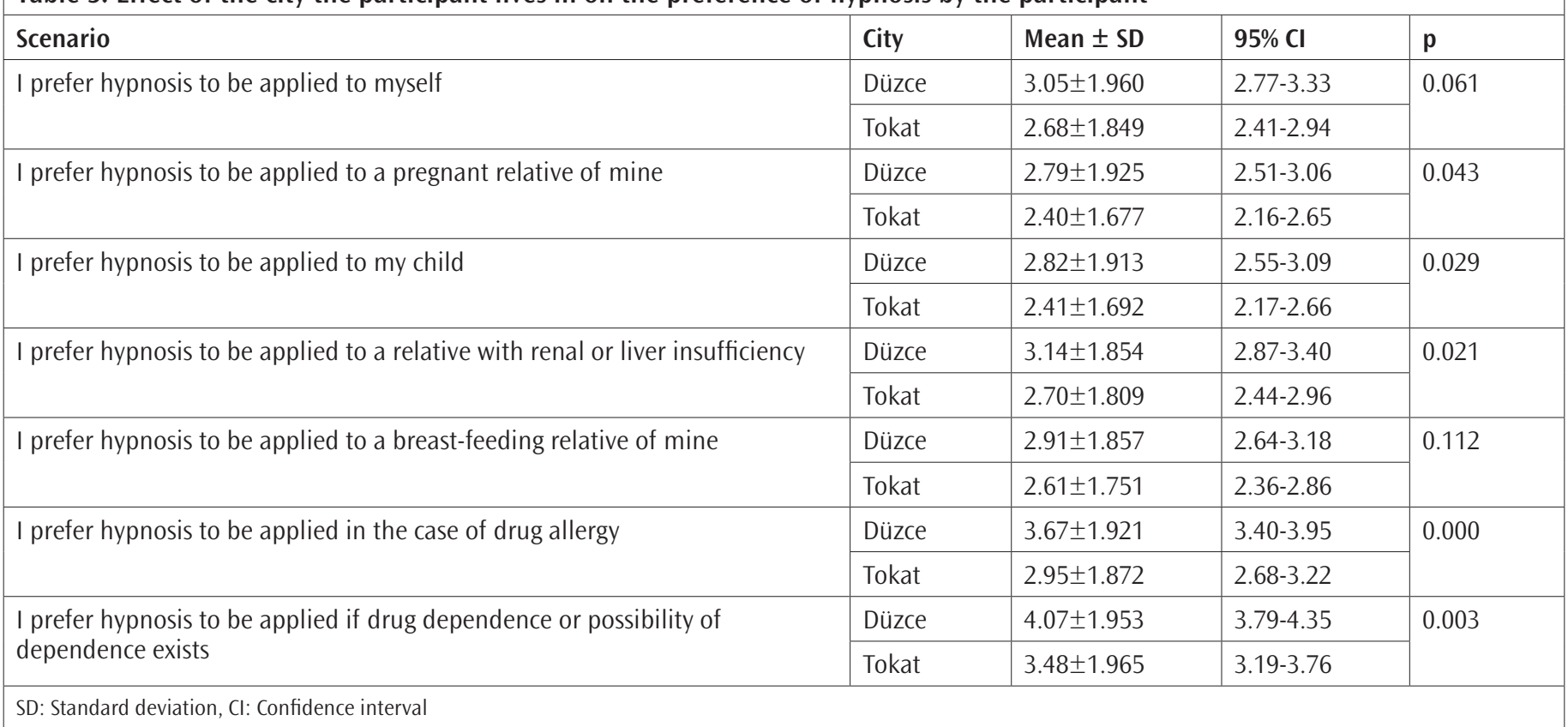




\begin{tabular}{|c|c|c|c|c|}
\hline Scenario & Education level & Mean \pm SD & $95 \% \mathrm{Cl}$ & $p$ \\
\hline \multirow{5}{*}{ I prefer hypnosis to be applied to myself } & Literate & $1.63 \pm 1.768$ & $0.15-3.10$ & \multirow{5}{*}{0.461} \\
\hline & Primary school graduate & $2.83 \pm 1.955$ & $2.33-3.32$ & \\
\hline & Secondary school graduate & $2.85 \pm 2.011$ & $2.25-3.44$ & \\
\hline & High school graduate & $2.91 \pm 1.868$ & $2.59-3.23$ & \\
\hline & University graduate & $2.93 \pm 1.910$ & $2.59-3.28$ & \\
\hline \multirow{5}{*}{$\begin{array}{l}\text { I prefer hypnosis to be applied to a pregnant relative } \\
\text { of mine }\end{array}$} & Literate & $1.38 \pm 10.61$ & $0.49-2.26$ & \multirow{5}{*}{0.410} \\
\hline & Primary school graduate & $2.50 \pm 1.894$ & $2.03-2.97$ & \\
\hline & Secondary school graduate & $2.60 \pm 2.027$ & $1.99-3.21$ & \\
\hline & High school graduate & $2.64 \pm 1.770$ & $2.33-2.95$ & \\
\hline & University graduate & $2.64 \pm 1.733$ & $2.33-2.96$ & \\
\hline \multirow{5}{*}{ I prefer hypnosis to be applied to my child } & Literate & $2.11 \pm 2.205$ & $0.42-3.81$ & \multirow{5}{*}{0.879} \\
\hline & Primary school graduate & $2.54 \pm 1.891$ & $2.06-3.02$ & \\
\hline & Secondary school graduate & $2.78 \pm 1.954$ & $2.20-3.36$ & \\
\hline & High school graduate & $2.63 \pm 1.749$ & $2.33-2.93$ & \\
\hline & University graduate & $2.63 \pm 1.785$ & $2.31-2.95$ & \\
\hline \multirow{5}{*}{$\begin{array}{l}\text { I prefer hypnosis to be applied to a relative with renal } \\
\text { or liver insufficiency }\end{array}$} & Literate & $1.00 \pm 0.000$ & $1.00-1.00$ & \multirow{5}{*}{0.013} \\
\hline & Primary school graduate & $2.72 \pm 1.915$ & $2.24-3.20$ & \\
\hline & Secondary school graduate & $2.78 \pm 2.021$ & $2.18-3.38$ & \\
\hline & High school graduate & $2.91 \pm 1.734$ & $2.61-3.21$ & \\
\hline & University graduate & $3.20 \pm 1.837$ & $2.88-3.53$ & \\
\hline \multirow{5}{*}{$\begin{array}{l}\text { I prefer hypnosis to be applied to a breast-feeding } \\
\text { relative of mine }\end{array}$} & Literate & $1.38 \pm 1.061$ & $0.49-2.26$ & \multirow{5}{*}{0.108} \\
\hline & Primary school graduate & $2.86 \pm 1.884$ & $2.39-3.33$ & \\
\hline & Secondary school graduate & $2.47 \pm 1.727$ & $1.95-2.99$ & \\
\hline & High school graduate & $2.72 \pm 1.811$ & $2.41-3.04$ & \\
\hline & University graduate & $2.96 \pm 1.796$ & $2.63-3.28$ & \\
\hline \multirow{5}{*}{$\begin{array}{l}\text { I prefer hypnosis to be applied in the case of drug } \\
\text { allergy }\end{array}$} & Literate & $1.63 \pm 1.188$ & $0.63-2.62$ & \multirow{5}{*}{0.157} \\
\hline & Primary school graduate & $3.32 \pm 1.950$ & $2.83-3.81$ & \\
\hline & Secondary school graduate & $3.39 \pm 2.092$ & $2.77-4.01$ & \\
\hline & High school graduate & $3.32 \pm 1.890$ & $3.00-3.64$ & \\
\hline & University graduate & $3.43 \pm 1.910$ & $3.09-3.77$ & \\
\hline \multirow{5}{*}{$\begin{array}{l}\text { I prefer hypnosis to be applied if drug dependence or } \\
\text { possibility of dependence exists }\end{array}$} & Literate & $2.89 \pm 2.315$ & $1.11-4.67$ & \multirow{5}{*}{0.504} \\
\hline & Primary school graduate & $3.68 \pm 1.977$ & $3.19-4.17$ & \\
\hline & Secondary school graduate & $3.54 \pm 2.126$ & $2.91-4.17$ & \\
\hline & High school graduate & $3.87 \pm 1.904$ & $3.54-4.20$ & \\
\hline & University graduate & $3.89 \pm 1.983$ & $3.54-4.25$ & \\
\hline
\end{tabular}

formed approximately one third of the study population. The young group included those participants between 18 and 25 years of age most of whom were students and those graduated school but still had not begun to work in a job. So, it was suggested that their perception of hypnosis might be different from those of the other groups which were formed by younger and middle-aged adults. However, the results did not support this hypothesis because the age groups were seen to not differ in terms of the preference of hypnosis. As far as we know, there are no previous studies evaluating the knowledge level, beliefs and 
attitudes of ED patients and their relatives related to hypnosis so we do not have any previous similar reports to compare with the results of the present study. However, Johnson and Hauck (17) conducted a study to evaluate the general public's perception of hypnosis. The study included four different groups formed by the respondents from different backgrounds and age groups. The authors stated that ideas and beliefs of the groups about hypnosis are remarkably consistent. The groups evaluated in the study by Johnson and Hauck (17) had both some similarities and some differences compared to the groups formed with regard to age of the participant in the present study but it is worth mentioning that the results of both studies are similar; different age groups have nearly the same perception of hypnosis. Barling and De Lucchi (18) reported that age did not affect the knowledge level, attitudes and beliefs about clinical hypnosis in both hypnosis-experienced and non-experienced participants. The results of that study also were similar to those of the current study in terms of the effect of age.

Gender distribution of the participants was near equal in the current study, although the number of male participants being higher than that of female participants. It was seen that understanding of hypnosis and ideas about its use in ED did not differ between the genders. In the study by Johnson and Hauck (17), the group a great majority of which was formed by women only stated that they agree to some extent with the statement "I would like to be hypnotized" which indicated that women may be more likely to choose hypnosis to be applied to the participant's herself. Whereas, it was seen, in the present study, that female participants did not differ from males in terms of willingness to application of hypnosis to themselves. Besides, they seemed to think about in the same way with the male participants even in the case of pregnancy or breast-feeding.

A really small minority of the participants stated that they had been hypnotized previously. The authors had suggested that a significant difference would be found between the previouslyhypnotized and non-hypnotized groups with regard to their knowledge level and thoughts about hypnosis and attitudes towards its use in ED. However, the results were not as suggested to be; the participants with previous hypnosis experience and those without a personal experience of hypnosis did not differ significantly in terms of their attitudes towards hypnosis. In the study by Barling and De Lucchi (18), it was seen that hypnosisexperienced participants were more knowledgeable and more likely to accept clinical use of hypnosis compared to those without previous hypnosis experience. We suggest that "no significant differences" between the groups, in the present study, might be a result of the extremely small number of hypnosisexperienced participants because there were just 13 participants who had a prior hypnosis experience.
More than half of the participants had graduated from high school, and nearly one third of the participants were university graduates. In the study by Johnson and Hauck (17), 96\% of the participants were high school graduates and more than three fourths of them continued their education after high school. So, education level of our participants was lower than that of the participants of the study by Johnson and Hauck (17). Because, the present study was conducted in a developing country and Johnson and Hauck's (17) study was conducted in a developed country, this difference in the education level of the participants is not so surprising. Whereas, nearly $98 \%$ of our participants were at least primary school graduates and all of them were literate which makes us to suggest they can understand and accurately interpret information on hypnosis they have gathered from different sources.

The participants were also evaluated with regard to their occupations, and it was seen that more than one third of the participants were wage workers followed by students which formed nearly one fifth of all participants. Wage workers formed the largest group because all participants working in different sectors on fee-earning basis were included in this group. One of the suggestions of the authors was that different occupation groups might exhibit different results but it was seen that occupation groups did not differ in terms of their perception of hypnosis. A possible reason for this result may be accumulation of all fee-earning workers in the same group but there would be more than 20 different occupation groups if more specific groups had been formed and most of these groups would include really small numbers of participants, and that could cause the results to become less reliable even if some significant findings could be detected. Thus, a broader classification was preferred.

Effect of different information sources on knowledge of the participants about hypnosis was evaluated, and it was seen that the source with the highest effect was television. It was the only information source having more or less effect on the knowledge of more than half of the participants. Television is followed by movies, rumors and stage hypnosis shows. Unfortunately, all of these sources are actually misleading; they rarely provide accurate information. Hypnosis specialists/clinicians and teachers could find a place at the end of the list just before friends and the other sources, respectively. These findings suggest that the participants had not had the chance to acquire accurate information about hypnosis. Barling and De Lucchi (18) also saw that participants who had not been hypnotized previously gathered their knowledge about hypnosis mostly from television or stage shows. We suggest that if educative television programs providing the real facts of hypnosis are made, the population's correct knowledge level can be increased considerably. 
After the first part including socio-demographic features and sources of information, the questionnaire included 14 Likert type statements about hypnosis and hypnotized person. This part of the questionnaire aimed to evaluate the knowledge level and beliefs of the participants about hypnosis. Means of the responses of the participants were below 3.5 for 3 statements only. One of these statements -the statement with the lowest mean value- was "Hypnotized person can terminate the hypnotic state whenever he wants to do so". A mean value below 3.5 in this item means the participants believe the hypnotized person cannot terminate the hypnotic state even if he wants to do so. A person believes he or she cannot terminate hypnosis although he wants to do so cannot be supposed to want hypnosis applied to him or her or to a relative. This finding indicates that the participants have fear of "remaining hypnotized forever". The other two parameters with mean scores less than 3.5 were "A person can be hypnotized even if he does not want to be." and "Hypnosis is formed by the person's own imagination." Less than 3.5 points in the former one means the participants mostly believe that a person cannot be hypnotized if he or she does not want to be, and that is true, hypnosis necessitates the patient's cooperation with the hypnotist. Less than 3.5 points in the latter one indicates the participants mostly disagree hypnosis is a function of the participant's own imagination. Actually, this also is partly true because it is not solely a result of imagination but it rather requires more than imagination. All other statements were given mean scores greater than 3.5, and these results collectively show that the participants mostly have a negative perception of hypnosis. For example, they think hypnotized person is totally controlled by the hypnotist, can be made to do something against his or her will and cannot keep his or her own secrets. One of the statements given a mean score greater than 3.5 was "Hypnotized person does not feel any pain". That suggests the participants think hypnosis is effective against pain. There were two other statements with means of greater than 3.5: "Hypnotized person forgets what happened during hypnotic state if he is ordered to do so" and "Deeply hypnotized ones are likely to forget what happened during hypnotic state". It is a positive finding that the participants gave responses which resulted in mean values greater than 3.5 in these statements because these scores may indicate the participants believe hypnosis can make it possible for a patient to forget unpleasant feelings like pain, anxiety and fear occurred during a painful state or procedure. On the other hand, these mean values may also reflect why the participants are afraid of hypnosis because they believe that the hypnotized person is totally controlled by the hypnotist and he or she forgets what happened during hypnotic trance. Combination of these two ideas may result in increased level of fear and anxiety about hypnosis. Finally, one can state that participants mostly do not have a positive perception of hypnosis although some statements resulted in mean scores suggestive of positive feelings about hypnosis. In fact, this is not so surprising because as it was mentioned above sources of information having the greatest influence on the knowledge of the participants about hypnosis were television, movies, rumors and stage shows which mostly provide inaccurate information. Misleading information including myths and misconceptions results in negative feelings and fear of hypnosis (19).

The last part of the questionnaire was about the willingness of the participants to application of hypnosis in ED. It was surprising for the authors to saw that mean of the participants' responses resulted in a value greater than 3.5 in just one statement which was about use of hypnosis in the existence or possibility of drug dependence. The participants seemed to not prefer application of hypnosis instead of drugs even in the case of pregnancy, pediatric age group, renal or liver insufficiency, breast-feeding period and drug allergy. Those results indicate that the participants are really so afraid of hypnosis that they will not approve its application even if the patient has allergy to the analgesic and sedative drugs. We suggest that the reason for the approval of hypnosis instead of drugs in the case of drug dependence can be common use of illegal drugs in Düzce where half of the participants were recruited from. Although Düzce is a small city, because it is located on the road of illegal drug trafficking in Turkey, illegal drug use is relatively more common in Düzce compared to similar small cities (20). Hence, people living in Düzce are familiar with damaging effects of drug dependence on both the person himself and his family; it is a suggested finding that they are going to be more likely to prefer alternative methods in the case or possibility of drug dependence. Since no previous studies, evaluating preference of hypnosis by the ED patients and their relatives, was found in English literature, the results of the present study could not be compared to those of a similar study. However, a study by McIntosh and Hawney (21) showed that patients whose knowledge on hypnosis was gathered primarily from television or stage shows held unfavourable views of hypnosis, and they would not be willing to accept hypnosis-based treatments in general Although that study was not conducted on ED patients or their relatives it provides information on approach of the general population to hypnosis.

It was seen, in the present study, that gender, age, occupation and previous personal hypnosis experience do not significantly affect the attitude of the participant towards use of hypnosis in ED. However, the city the participant lives in seemed to affect the preference of the participant in all suggested scenarios except application of hypnosis to the participant's himself or to a breast-feeding relative. Although, means of the responses 
of participants living in Düzce were higher than those of the participants living in Tokat, the only scenario which had a mean value of greater than 3.5 was existence or possibility of drug dependence. In this scenario, mean value of the responses of the participants living in Düzce was 4.07. Actually, mean value of the responses of participants living in Tokat also was really closer to 3.5 (mean: 3.48 ) but it was still smaller than it. As it was mentioned above, use of illegal drugs and drug dependence is really common in Düzce (20). Thus, it was suggested that people living in Düzce are familiar with the problems related to drug dependence so they supported use of hypnosis in the case of existence or possibility of drug dependence. Education level was the second socio-demographic feature which was seen to affect the preference of the participant but its effect reached statistical significance in only one suggested scenario which is renal or liver insufficiency. It was seen that as the education level of the participant increases the likelihood the participant approves use of hypnosis instead of drugs increases also. However, even the mean value of the responses of university graduates was smaller than 3.5 which indicates hypnosis was not preferred over drugs even by the participants in this "highest education level" group.

\section{Study Limitations}

The current study has some limitations: First, it was performed in two centers in different cities but both cities are small ones so a new study conducted in a higher number of centers which also include some centers in metropolises may provide more certain results. Second, the study included ED patients and their relatives but these patients had not needed sedation or analgesia during the visit they participated in the study. However, this may also be considered as strength of the study because the results of the study reflect the opinion of all ED patients and their relatives, and we suggest that it reflects the general public's opinion better. Third, the study did not include pediatric patients. Unlike adults, children in stressful conditions are already considered in the first stage of hypnosis, and so are generally more susceptible to hypnotic suggestions which means they are more hypnotizable $(3,22)$. However, they cannot decide to accept the application of hypnosis by themselves if their parents do not agree with them. Finally, older adults were not included in the study due to the concerns about possible mental and cognitive impairments in this group. Actually, this group is more likely to have renal or liver insufficiency and use multiple drugs which may interact with analgesic and sedative drugs. But, it was not possible, in the ED setting, to reliably determine which patients or relatives above 65 years of age did not have any cognitive impairment so this group was not included in the study.

\section{Conclusion}

Television has the highest effect on the participants' knowledge on hypnosis and was followed by movies, rumors and stage hypnosis shows. It seems like these sources resulted in the accumulation of common misleading information in the participants' mind and caused them to approach hypnosis with caution. The participants were seen to be reluctant to prefer hypnosis in any clinical scenario except the existence or possibility of drug dependence. Gender, age, occupation and personal hypnosis experience were seen to not have a significant effect on the attitude of the participant towards hypnosis. The city the participant lives in and education level of the participant were seen to affect the preference of the participants in some clinical scenarios however the effect of education level remained as a "just statistically significant" effect; it did not reach clinical significance because even the most educated group was unwilling to prefer hypnosis. So, the city the participant lives in was the only parameter which seemed to change the overall preference of the study population in at least one clinical scenario which was existence or possibility of drug dependence. Finally, we suggest that, before starting to think about using hypnosis techniques in $\mathrm{ED}$, the population should be educated on hypnosis so that people can get rid of common myths and misconceptions about hypnosis, and the most promising tool which can be used to change the public's view of hypnosis is television which seems to be the main source of misleading information for now.

\section{Acknowledgements}

We would like to thank Emine Ayhan Emektar of Balıkesir University School of Medicine Public Health Department for her invaluable contributions to statistical analysis of the study data.

\section{Ethics}

Ethics Committee Approval: The study had been approved by Düzce University Non-invasive Health Studies Ethics Committee (approval number: 2017/46, approval date: 06.03.2017).

Informed Consent: Written informed consent had been taken from each participant.

Peer-review: Externally peer-reviewed.

\section{Authorship Contributions}

Concept: H.G., Design: H.G., Data Collection or Processing: H.G., S.K., Analysis or Interpretation: H.G., S.K., Literature Search: H.G., Writing: H.G.

Conflict of Interest: No conflict of interest was declared by the authors.

Financial Disclosure: The authors declared that this study received no financial support. 


\section{References}

1. Iserson KV. An hypnotic suggestion: review of hypnosis for clinical emergency care. J Emerg Med. 2014;46:588-96.

2. Deltito JA. Hypnosis in the treatment of acute pain in the emergency department setting. Postgrad Med J. 1984;60:263-6.

3. Iserson KV. Hypnosis for pediatric fracture reduction. J Emerg Med. 1999;17:53-6.

4. Birnie KA, Noel M, Parker JA, Chambers CT, Uman LS, Kisely SR, et al. Systematic review and meta-analysis of distraction and hypnosis for needlerelated pain and distress in children and adolescents. J Pediatr Psychol. 2014;39:783-808

5. Accardi MC, Milling LS. The effectiveness of hypnosis for reducing procedurerelated pain in children and adolescents: a comprehensive methodological review. J Behav Med. 2009;32:328-39.

6. Wood C, Bioy A. Hypnosis and pain in children. J Pain Symptom Manage. 2008;35:437-46

7. Catoire P, Delaunay L, Dannappel T, Baracchini D, Marcadet-Fredet S, Moreau 0 , et al. Hypnosis versus diazepam for embryo transfer: a randomized controlled study. Am J Clin Hypn. 2013;55:378-86.

8. Güler N. SS-584 Hipnosis in an emergency department, less chemistry, saving time. In: Proceedings of the 5th Intercontinental Emergency Medicine Congress; 2018; Apr 19-22; Antalya, Turkey. 2018.p.243.

9. Levine JD, Gordon NC, Fields HL. The mechanism of placebo analgesia. Lancet. 1978;2:654-7.

10. Goldstein A, Hilgard ER. Failure of the opiate antagonist naloxone to modify hypnotic analgesia. Proc Natl Acad Sci USA. 1975;72:2041-3.
11. Bierman SF. Hypnosis in the emergency department. Am 」 Emerg Med. 1989;7:238-42.

12. Goldie L. Hypnosis in the Casualty Department. Br Med J. 1956;2:1340-2.

13. Iserson K. Relocating dislocations in a wilderness setting: use of hypnosis. J Wild Med. 1991;2:22-6.

14. Kohen DP. Applications of relaxation/mental imagery (self-hypnosis) in pediatric emergencies. Int J Clin Exp Hypn. 1986;34:283-94.

15. Paris PM. Pain management in the child. Emerg Med Clin North Am. 1987; 5:699-707.

16. Wain HJ, Amen DG. Emergency room use of hypnosis. Gen Hosp Psych. 1986;8:19-22.

17. Johnson ME, Hauck C. Beliefs and opinions about hypnosis held by the general public: a systematic evaluation. Am J Clin Hypn. 1999;42:10-20.

18. Barling NR, De Lucchi AAG. Knowledge, attitudes and beliefs about clinical hypnosis. Aust J Clin Exp Hypn. 2004;32:36-52.

19. Green JP. Beliefs about hypnosis: popular beliefs, misconceptions, and the importance of experience. Int J Clin Exp Hypn. 2003;51:369-81.

20. Kizilkoyun F. Türkiye'nin uyușturucu haritası - Turkey’s Illegal Drug Map 2015. Available from: https://www.hurriyet.com.tr/gundem/turkiye-ninuyusturucu-haritasi-30163594

21. McIntosh IB, Hawney M. Patient attitudes to hypnotherapy in a general medical practice: a brief communication. Int J Clin Exp Hypn. 1983;31:21923.

22. Butler LD, Symons BK, Henderson SL, Shortliffe LD, Spiegel D. Hypnosis reduces distress and duration of an invasive medical procedure for children. Pediatrics. 2005;115:e77-85. 